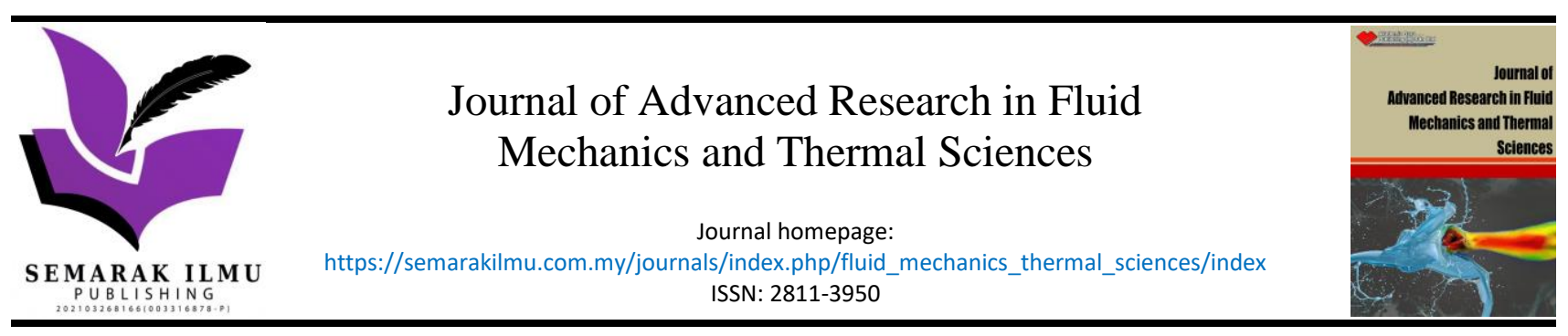

\title{
Modelling and Validating the Spray Characteristics of a Co-axial Twin-Fluid Atomizer Using OpenFOAM
}

\author{
Shriram Sathishkumar ${ }^{1}$, Bommisetty Sambasiva Rao ${ }^{1}$, Sidharth Pradeep ${ }^{1}$, Solai Sairam R. M. ${ }^{1}$, Balaji \\ Kalaiarasu ${ }^{1}$, Prabhu Selvaraj ${ }^{1, *}$ \\ 1 Department of Mechanical Engineering, Amrita School of Engineering, Amrita Vishwa Vidyapeetham, Coimbatore, 641112, India
}

ARTICLE INFO ABSTRACT

\section{Article history:}

Received 29 June 2021

Received in revised form 30 November 2021

Accepted 2 December 2021

Available online 17 January 2022

\begin{abstract}
Today, the applications of sprays cover a wide range of fields. Their role in internal combustion engines is instrumental in maintaining higher engine efficiency. A deeper understanding of the liquid-gas phase interaction in sprays is crucial to the atomization process. The methods and models used in the simulations have their challenges due to the various discretization schemes and solutions used. To develop and validate the computational models, well defined experimental data is required. In the present work, spray characteristics were studied numerically through OpenFOAM. As the spray characteristics are closely linked with the liquid breakup length, this study focuses on the primary breakup phenomena and the breakup length of the liquid jet emanating from the twin-fluid co-axial flow atomizer. Numerical simulations were performed for a wide range of initial conditions and the breakup length of the spray was validated against the experimental observed by Sivadas et al., [26]. These simulations were carried out using a Eulerian based VOF solver that models the fluid as a continuum. KEpsilon model was used to predict the turbulent nature of the spray. The air and water velocities were varied between 19.0 to $31.3 \mathrm{~m} / \mathrm{s}$ and 0.7 to $1.8 \mathrm{~m} / \mathrm{s}$ respectively. The proposed model was able to predict the computed breakup length within $20 \%$ of the experimental values. The present model can be further extended to test for a co-axial swirl injector to predict finer spray formation.
\end{abstract}

\section{Keywords:}

OpenFOAM; spray characteristics; Eulerian method; VOF

\section{Introduction}

Atomization is the process of disintegration of a liquid jet into finer spray by active or passive methods. Passive methods depend upon the atomizer designs. Active methods include co-axial or parallel air flow, electrostatic force and ultrasonic waves. An experimental study conducted by Sivadas et al., [1] illustrated the optimum length of the windpipe which transmits the acoustic energy to the cavity of the twin-fluid atomizer from the compression driver. This enhances the liquid column breakup process. Effervescent Atomizer is another active atomization, on which an experimental study was conducted by Sivadas et al., [2] to determine the spray characterisation of the liquid jet. These studies demonstrated that active atomization has better spray characteristics than passive

\footnotetext{
* Corresponding author.

E-mail address: s_prabhu1@cb.amrita.edu
}

https://doi.org/10.37934/arfmts.91.1.3545 
atomization. The jet breaks up under four different regimes - Rayleigh jet breakup, First-wind induced breakup, Second-wind induced breakup and Finer atomization zone. The type of regime that is followed is determined by the value of the weber number. There is a wide range of applications of atomization in different fields such as crop spraying, nebulisers, spray painting, spray cooling, film coating, powder metallurgy, combustion engines.

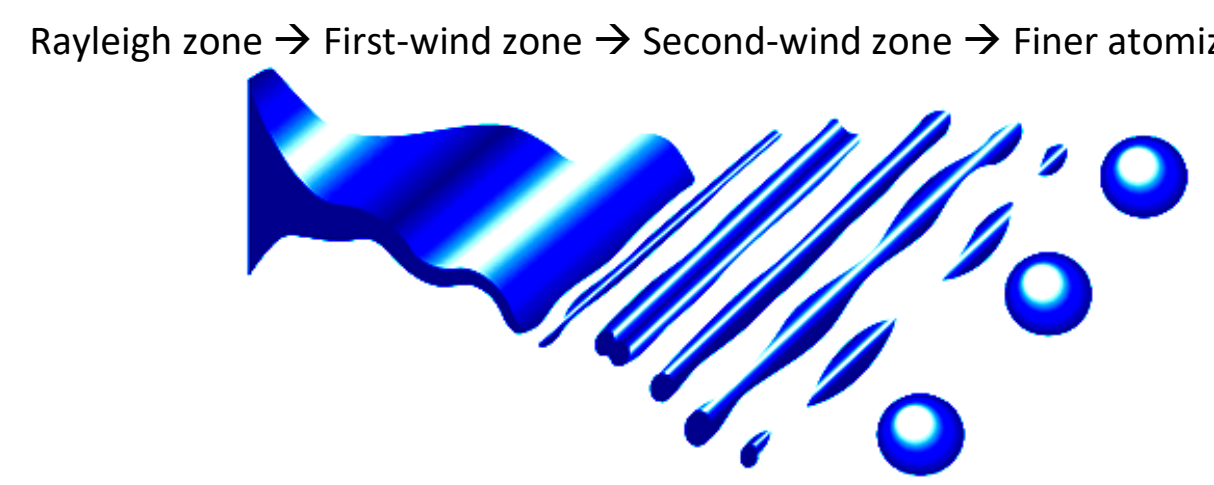

Fig. 1. Various breakup regimes [3]

Quite a few experimental and highly theoretical studies have been undertaken to explore the atomization process involved in a co-axial twin fluid atomizer. The studies by Lefebvre and McDonell [4], Chigier [5] and Liu et al., [6] have noted the influence that the co-axial airflow had on the liquid jet and how it affected the stability of the liquid jet at the interface between the liquid and the flowing air. Along with the initially known forces that affect the jet's stability, such as the aerodynamic, viscous and surface tension forces, the research by Fraser et al., [7] led into the effect of the surface roughness at liquid orifice exit.

For an internal combustion engine to work at its best efficiency, the injected fuel must be atomized into a fine spray with the oxidiser (air). This ensures that this fine spray of air and fuel will combust completely, giving the full energy output from the air-fuel mixture. Various types of injectors design that are available today are discussed by Bayvel and Orzechowski [8]. The efficiency of an atomizer is assessed by the longitudinal distance it takes to create a fine spray from the injection position. This distance is characterised by the breakup length and the magnitude of this parameter closely relates to the characteristics of the spray. The parameters involved are discussed by Soni and Kolhe [9]. The nozzle of an injector can have different shapes. However, the stability of the spray comes into question. The experimental studies by Wang and Fang [10] determined rectangular and other jet shapes were very unstable compared to the circular jets at low velocities. However, at high velocities, the rectangular jet's stability was similar to that of the circular ones. According to the refining techniques, liquid atomizers are classified into several types, such as twin-fluid atomizer, rotary atomizer, single fluid pressure atomizer and electrostatic atomizer. The design of different atomizers and their specifications were illustrated in detail by Lefebvre and McDonell [4].

The experimental investigations conducted by Agrawal et al., [11] and Balla et al., [12] determined the hydrodynamics of a non-spherical liquid droplet falling through air. The study was done by comparing the height to width ratio of the droplet. In a combined experimental and computational study conducted by Murugan et al., [13] on a twin-fluid coaxial atomizer, the effect of Air-Liquid Ratio of the mode of atomization of the liquid was determined. For lower ALR values, the atomizer worked in a flow-focussing mode and for ALR values higher than 0.6, it worked in a flowburring mode. It was also observed that for a large L/D value, a significantly higher number of microjets were formed within the atomizer. In another experiment conducted by Soni et al., [14] the critical Weber number was found to decrease, when the cross-air flow was moved towards a more 
inline flow. The time required for the droplet to breakup also decreased when the air flow was moved towards a more inline position.

The difference in the velocities between air and fuel is proportional to the forces that act on the surfaces of the two fluids. These forces cause the fluid to break up. The magnitude of difference in the velocity determines the liquid atomization breakup mechanism. This was supported by Lefebvre and Ballal [15]. The diameter and pressures at which the liquid is injected by the atomizer dictate the spray characteristics. It was determined through numerical simulations done by Andsaler et al., [16] that smaller injection diameter corresponds to a shorter breakup length, while larger injection pressures increased the penetration lengths of the spray. Both these characteristics increase the quality of the spray. By introducing perturbations into the airflow, the breakup distribution of the spray can be changed. From the experimental studies by Broumand et al., [17] the transition from one breakup regime to the other was delayed by increasing the intensity of the air perturbations. The breakup of liquid droplets can be affected by various parameters, the computational study by Aly et al., [18] on co-axial air blast atomizer focused on the effect of drag and turbulence on the breakup process. It was determined that turbulence played a major role. Jaat et al., [19] in their computational study compared the spray characteristics of various biodiesel blends injected from an atomizer under various pressures and temperatures. In the computational study by Seraj and Yahya [20] OpenFOAM was used to study the migration water droplets on a filter for different droplet velocities. They determined the liquid-volume fraction reduced with increasing velocity. Jumadi et al., [21] computationally studied the spray characteristics of petrol injected at various pressures to determine the most efficient air-fuel ratio.

A numerical simulation of an air-blast atomizer using OpenFOAM software is performed by Shafaee and Mahmoudzadeh [22] to evaluate the effects of geometrical parameters and flow conditions on spray characteristics of the jet. It is observed that at a specific Weber number, the Sauter mean diameter (SMD) increases with an increase in liquid port diameter, but for a higher weber number, this parameter has little to no effect on the SMD. The dimensions of a computational domain play a major role in the accuracy of the results and that the domain edges don't affect the fluid flow. Behr et al., [23] determined that the width of a computational domain should be 16 to 32 times the diameter. Based on this conclusion, the width of the domain was designed at 20 times the diameter of the water injector. The effect of liquid jet injection entry conditions on the structure of liquid jet in crossflow was determined by Prakash et al., [24] the experiment is carried out for a range of liquid to air momentum ratios and aerodynamic weber number. The exit conditions were controlled by different L/D ratios of the nozzle and the spray characteristics for laminar, turbulent and transition states were observed and analysed. An experimental and theoretical analysis of symmetrical and asymmetrical disturbances in the Rayleigh zone of an air-assisted liquid sheet was conducted by Sivadas et al., [25]. The experiment is carried out to get a better insight into the breakup by observing the temporal growth rate of the wave perturbations and extracting the wave number for the maximum growth rate, thus obtaining the breakup frequency. The breakup length is closely related to the characteristics of the spray. By considering the Eulerian model, the primary breakup length can be determined. As the breakup length is low, the jet has finer droplets when compared to the jet having a higher breakup length. There have been few numerical investigations in the area of spray atomization and most of the researches conducted was experimental. In the present study, a computation model is developed in order to determine the breakup length of a co-axial twin fluid atomizer and the spray characteristics were validated. 


\section{Methodology}

\subsection{Numerical Simulation}

The simulations were done using OpenFOAM. InterFoam is the solver that is used for the present study. This solver can solve the Navier-Stokes equation for two incompressible, isothermal and immiscible fluids. This means that the solver can be used for two fluids that won't usually mix and don't compress. For example, we are considering here water and air, where the air is assumed to be incompressible. At a particular region, the physical properties of either one of the fluids are present and are constant throughout except at the interphase of the fluids. This solver solves for the below three equations: Continuity equation, Momentum equation and the Interphase equation.

\subsubsection{Continuity equation}

It is constant density continuity equation:

$\frac{\partial u_{j}}{\partial u_{j}}=0$

\subsubsection{Momentum equation}

$\frac{\partial\left(\rho u_{i}\right)}{\partial t}+\frac{\partial}{\partial x_{j}}\left(\rho u_{j} u_{i}\right)=-\frac{\partial p}{\partial x_{i}}+\frac{\partial}{\partial x_{j}}\left(\tau_{i j}-\tau_{t_{i j}}\right)+\rho g_{i}+f_{\sigma i}$

$\mathrm{u}$ - velocity; $g_{\mathrm{i}}-$ Gravity; $\mathrm{p}$ - pressure; $\tau_{\mathrm{ij}}$ - Viscous Stress;

$\tau_{t_{i j}}-$ Turbulent stress; $f_{\sigma i}-$ Surface tension

Density is defined as:

$\rho=\alpha \rho_{\text {water }}+(1-\alpha) \rho_{\text {air }}$

For Inside Fluid (Water): $\alpha=1$ and density as $\rho_{\text {water. }}$

For Outside Fluid (Air): $\alpha=0$ and density as $\rho_{\text {air }}$.

Concentation of water $(\alpha)$ varies from 0 (air)to 1 (water) and $f_{\sigma}$ is Continum surface force.

$f_{\sigma}=\sigma K \frac{\partial \alpha}{\partial_{x_{i}}}$

Surface tension is $\sigma, \mathrm{K}$ is the curvature and is approximated as follows

$K=-\frac{\partial n_{i}}{\partial x_{i}}=-\frac{\partial}{\partial x_{i}}\left(\frac{\partial \alpha / \partial x_{i}}{\left|\partial \alpha / \partial x_{i}\right|}\right)$

\subsubsection{Interphase equation}

The equation for the interphase is solved to find interphase between the two fluids.

$\frac{\partial \alpha}{\partial \mathrm{t}}+\frac{\partial\left(\alpha u_{j}\right)}{\partial \mathrm{x}_{\mathrm{i}}}=0$ 


\subsection{Case Setup}

The working fluid is water and air. The properties of the fluids are shown in Table 1 . The computational grid consists of a 3-Dimensional cubic domain of dimensions $60 \times 60 \times 180 \mathrm{~mm}$ and meshed with elements of size $0.0001 \mathrm{~m}$ at its core. The number of elements in the mesh is 284,400 (Figure 2). Water is injected into the control volume through an inlet diameter of $0.003 \mathrm{~m}(\mathrm{~d})$. Air is injected through an annular area of diameters $0.012 \mathrm{~m}(\mathrm{~d} 1)$ and $0.009 \mathrm{~m}(\mathrm{~d} 0)$. The fluids are injected into the control volume that is at $1 \mathrm{~atm}$ pressure. The case is simulated for $0.3 \mathrm{~s}$ to improve the spray characteristics, flow profile and attain steady-state and convergence. The time step size is $1 \times 10^{-5} \mathrm{~s}$, with a maximum Courant number of 0.5 . The boundary conditions are tabulated in Table 2 . The turbulence model used in this study is the $k-\varepsilon$ model.

The pressure-velocity coupling is solved using the PIMPLE algorithm, which is a combination of PISO (pressure implicit with splitting of operator) and SIMPLE (Semi-implicit method for pressure linked equations) methods. The discretization of transient terms is based on the first-order Eulerian method, while other terms are discretized using the second-order Gaussian method.

Table 1

Physical properties of the fluids

\begin{tabular}{lll}
\hline Properties & Water & Air \\
\hline Density $\left(\mathrm{kg} / \mathrm{m}^{3}\right)$ & 1000 & 1 \\
Viscosity $\left(\mathrm{m}^{2} / \mathrm{s}\right)$ & $1 \times 10-6$ & $1.48 \times 10-5$ \\
Surface Tension, $\sigma(\mathrm{N} / \mathrm{m})$ & $0.07\left(\right.$ at $\left.25^{\circ} \mathrm{C}\right)$ & \\
\hline
\end{tabular}

Table 2

Boundary Conditions

\begin{tabular}{llllll}
\hline & Velocity & Pressure & a.water & $\mathrm{k}$ & $\varepsilon$ \\
\hline $\begin{array}{l}\text { Inlet } \\
\text { Water }\end{array}$ & fixedValue & $\begin{array}{l}\text { fixedFlux- } \\
\text { Pressure. }\end{array}$ & Calculated (1) & fixedValue & fixedValue \\
$\begin{array}{l}\text { Inlet } \\
\text { Air }\end{array}$ & fixedValue & $\begin{array}{l}\text { fixedFlux- } \\
\text { Pressure. }\end{array}$ & Calculated (0) & fixedValue & fixedValue \\
$\begin{array}{l}\text { Walls } \\
\text { Outlet }\end{array}$ & noSlip & $\begin{array}{l}\text { zeroGradient } \\
\text { zeroGradient }\end{array}$ & $\begin{array}{l}\text { fixedValue (0) } \\
(1 \text { atm) }\end{array}$ & kqRWallFunction & epsilonWallFunction \\
& & & zeroGradient & zeroGradient & zeroGradient \\
\hline
\end{tabular}

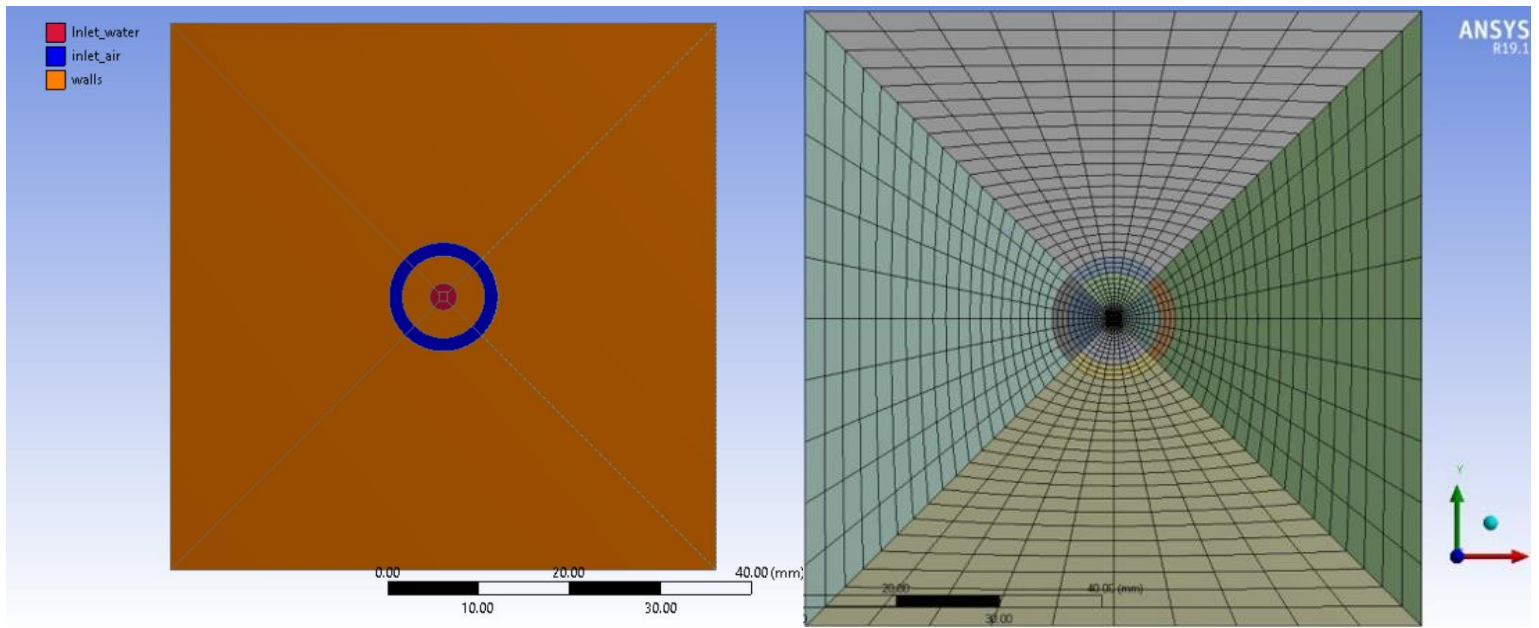

Fig. 2. Simulation domain geometry and mesh structure 


\section{Results and Discussion}

The simulations were done by varying the air velocities 19, 22.4, 24.5, 29 and $31.3 \mathrm{~m} / \mathrm{s}$. Each subset was simulated for five different water velocities of $0.7,1.1,1.2,1.6$ and $1.8 \mathrm{~m} / \mathrm{s}$ for a total of twenty-five cases. The experimental results had an uncertainty of $\pm 20 \%$. Figure 3 and Figure 4 show the velocity contours for two extreme cases of minimum and maximum breakup length at different time respectively. In Figure 3, the velocity of water is minimum at $0.7 \mathrm{~m} / \mathrm{s}$ and velocity of air is maximum at $31.3 \mathrm{~m} / \mathrm{s}$; and hence, has a minimum breakup length of $24.6 \mathrm{~mm}$. The breakup occurs predominantly due to the aerodynamic shear effect and the gravitational effects are neglected. Expansion of liquid at the exit plane may be due to a fall in pressure between the liquid and air streams with increasing air velocities. As the quality of spray is related to the breakup length, it can be considered for characterizing the spray phenomena. In witnessing the Figure 3 at different time frame the evolution is dominated by aerodynamic shear. In Figure 4, it is evident that the evolution of the breakup is dominated by liquid inertia and the nozzle wall thickness effects remain prominent. In this atomizer simulated the wall thickness effect prevents the coflowing air in order to enhance the breakup process. In Figure 4, it is vice versa with a maximum water velocity of $1.8 \mathrm{~m} / \mathrm{s}$ and a minimum air velocity of $19 \mathrm{~m} / \mathrm{s}$ that leads to maximum breakup length of $137.0 \mathrm{~mm}$. The atomization process is initialized from breaking of water column into ligaments due to the instability in surface tension. This phenomenon is accelerated in the presence of Aerodynamic shear. In a twin-fluid atomizer, the aerodynamic shear scraps off some water molecules from the water column which causes a retarding force into the water column forming a wave like perturbations. When the wave amplitude reaches the critical value, the areas of the site corresponding to half and full wavelength of the oscillation is torn away to form ligaments. Further due to the effect of Aerodynamic shear the ligaments are broken down into fine spray droplets. The surface tension and aerodynamic shear plays a prominent role in the atomization process.

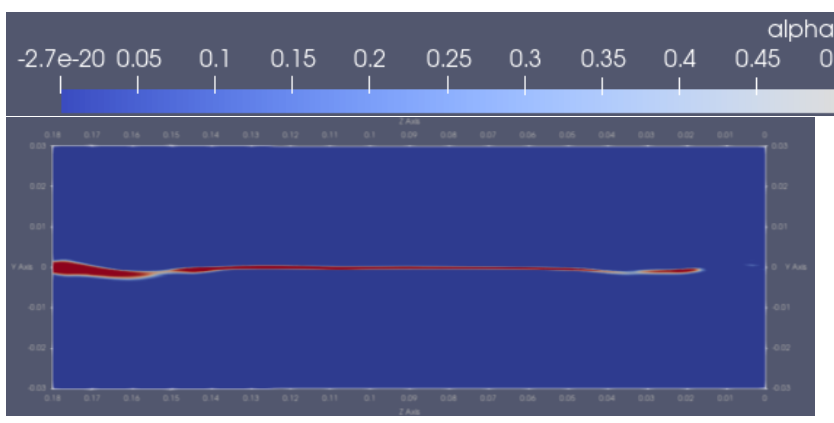

(a)

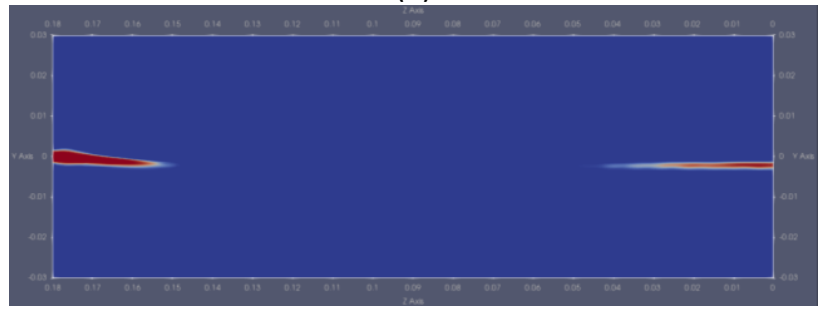

(c)

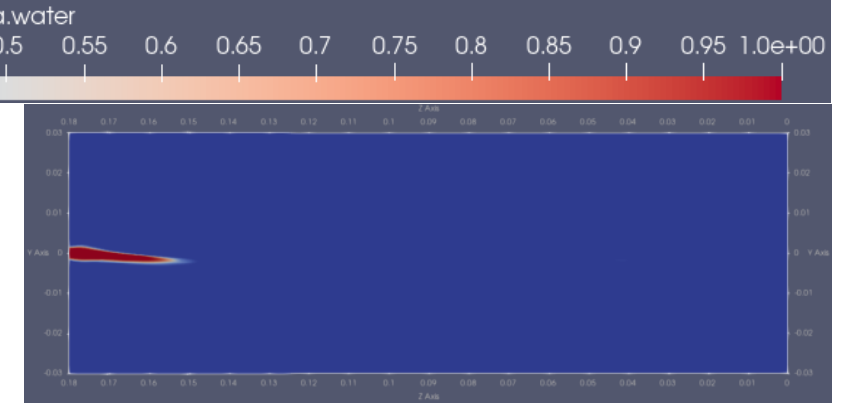

(b)

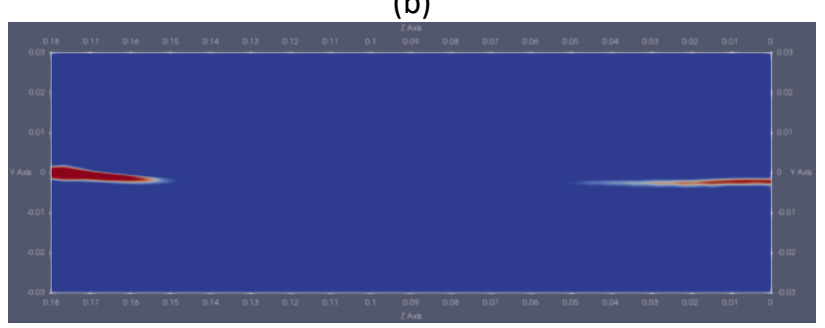

(d)

Fig. 3. (a)-(d) Void fraction of water at air velocity $31.3 \mathrm{~m} / \mathrm{s}$ and water velocity $0.7 \mathrm{~m} / \mathrm{s}$ at $0.05,0.1,0.15$, $0.2 \mathrm{~s}$ 


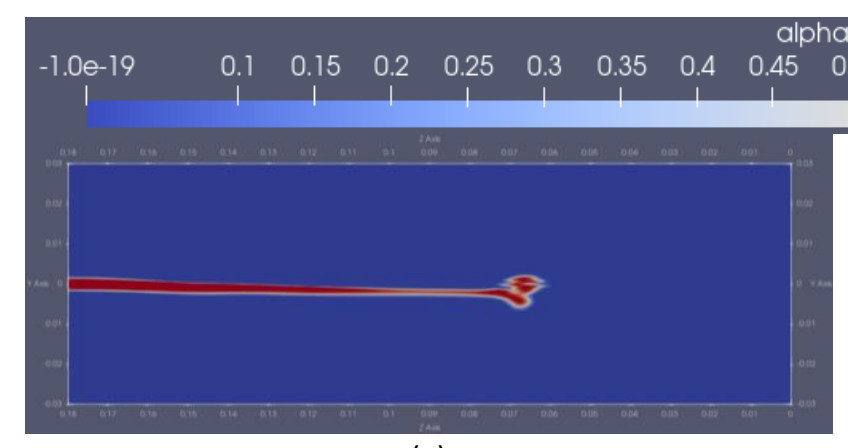

(a)

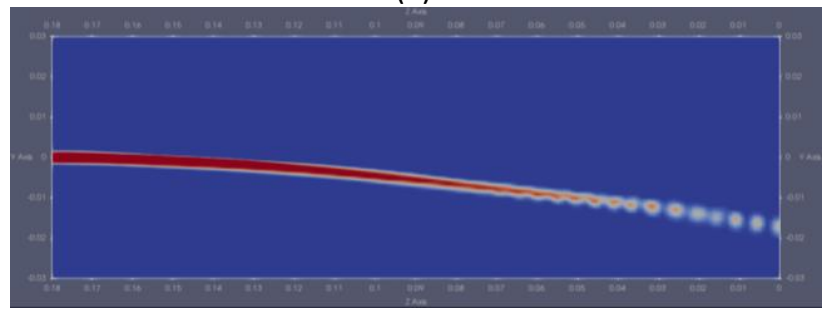

(c)

\section{pha.water}

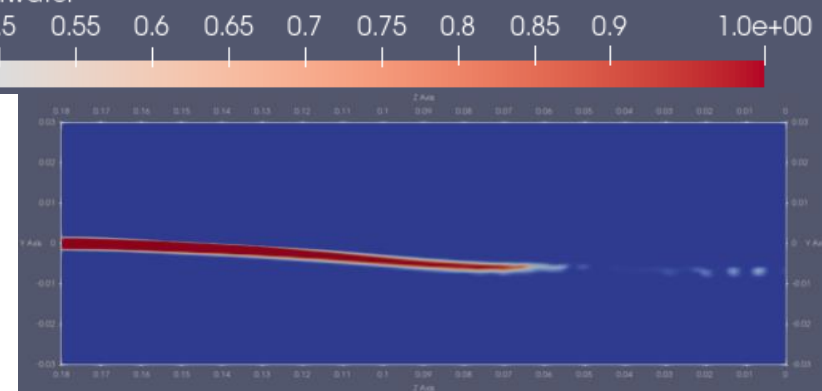

(b)

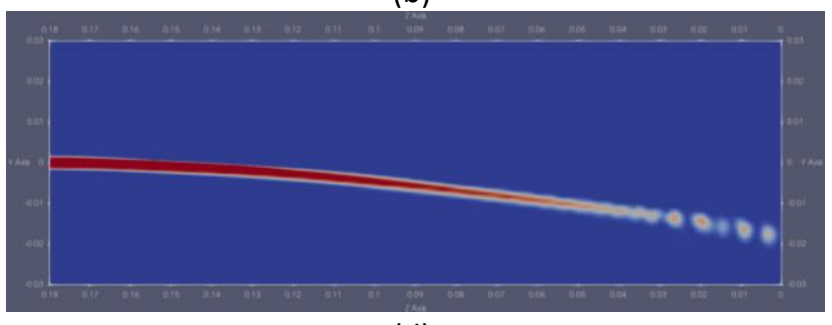

(d)

Fig. 4. (a)-(d) Void fraction of water at air velocity $19 \mathrm{~m} / \mathrm{s}$ and water velocity $1.8 \mathrm{~m} / \mathrm{s}$ at $0.05,0.1,0.15,0.2 \mathrm{~s}$

The obtained computational values were plotted against the experimental values obtained by Sivadas et al., [26] and the corrected lower and upper bounds values of the experimental values. The breakup lengths were plotted in Figure 5(a) to Figure 5(e). It's observed that at a lower water velocity $(0.7$ to $1.2 \mathrm{~m} / \mathrm{s})$, the break up is initialised by aerodynamic shear and at higher water velocities it's mainly due to surface tension. The average percentage error for Figure 5(a) to Figure 5(e) ranges between 19\%-22\%. In the Figure 5(a) and Figure 5(d), it is eminent that as the water velocity increases the simulation values diverges from the experimental data due to the numerical and modelling errors.

From the experimental and computational values in Figure 6, the breakup length increases with an increase in water velocity. However, for an increase in air velocity, the breakup length decreases. The breakup lengths for different cases were compared in Figure 6.

The simulated breakup lengths are non-dimensionalised by the injector diameter, and then plotted against the relative mass flow rate between the two fluids in Figure 7 . The breakup length increases for an increase in the relative mass flow rate. The relative flow rate is calculated using the formula $\dot{m}_{\text {water }} / \dot{m}_{\text {air }}$ (Eq. (7) and Eq. (8)). 


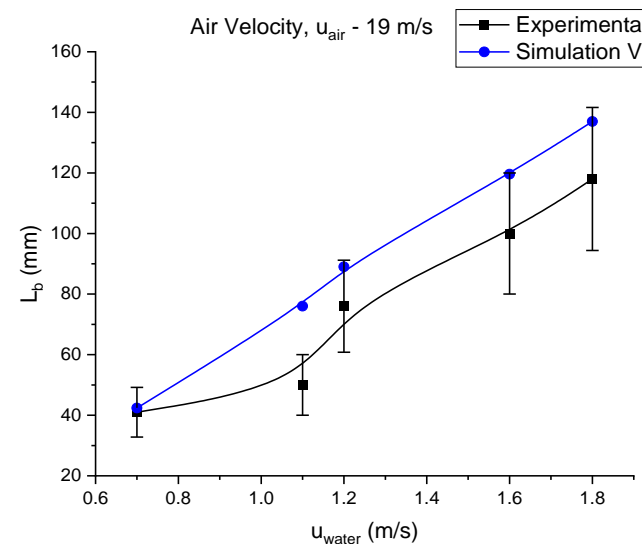

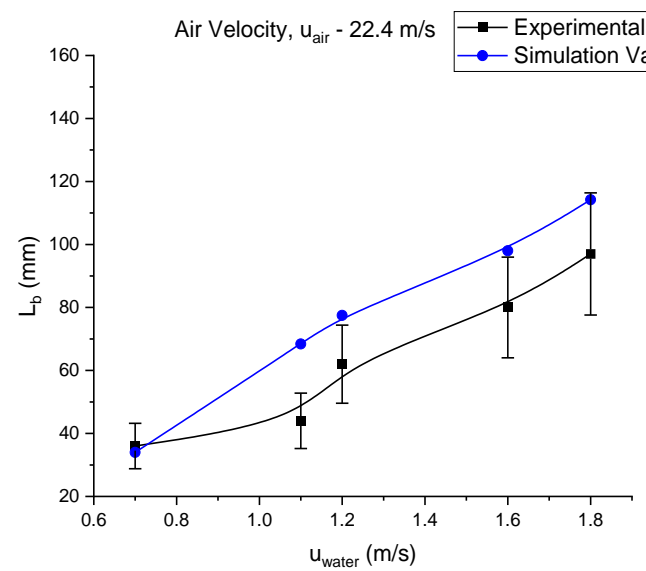

(b)

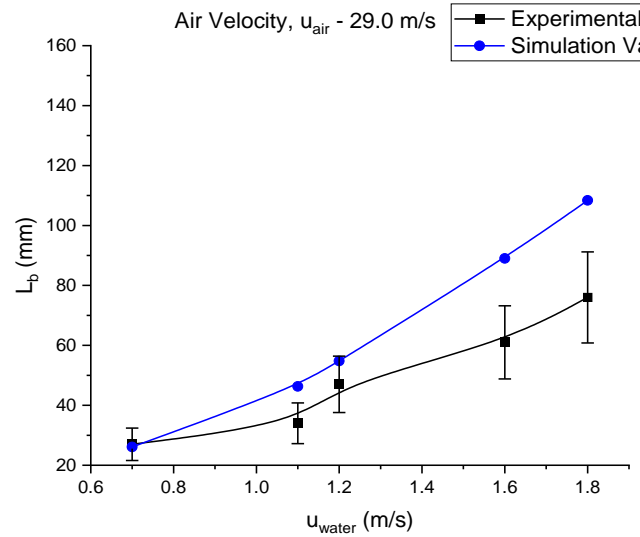

(d)

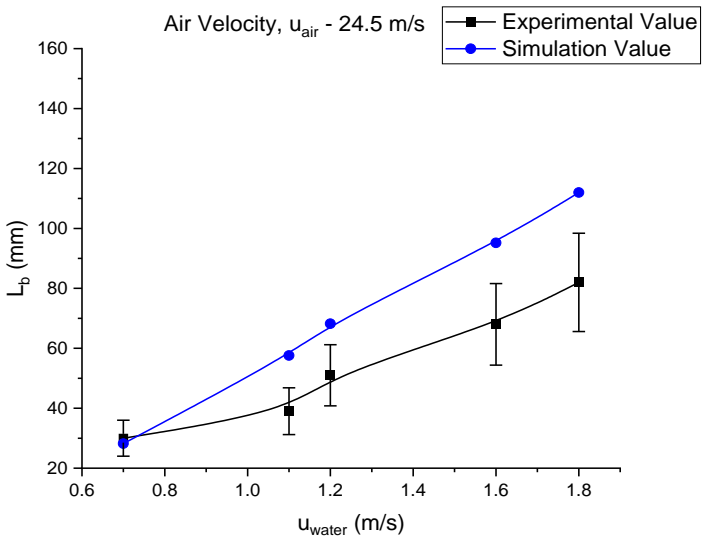

(c)

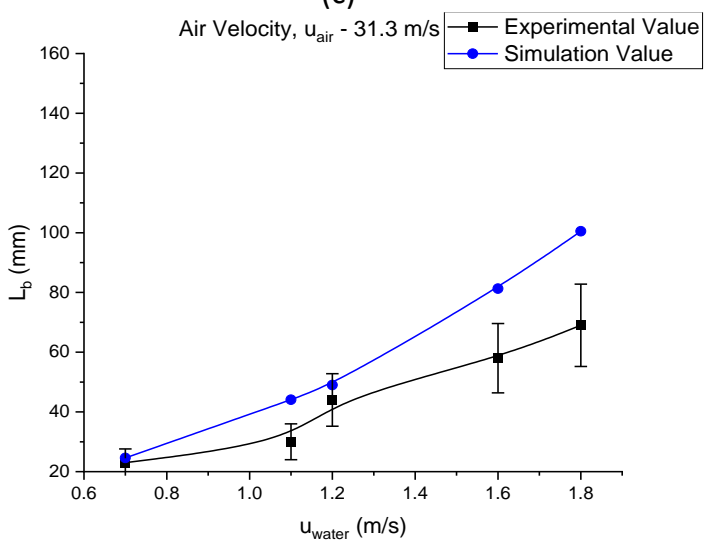

(e)

Fig. 5. (a)-(e) Breakup length comparison at different air velocities with the experiment [26] 


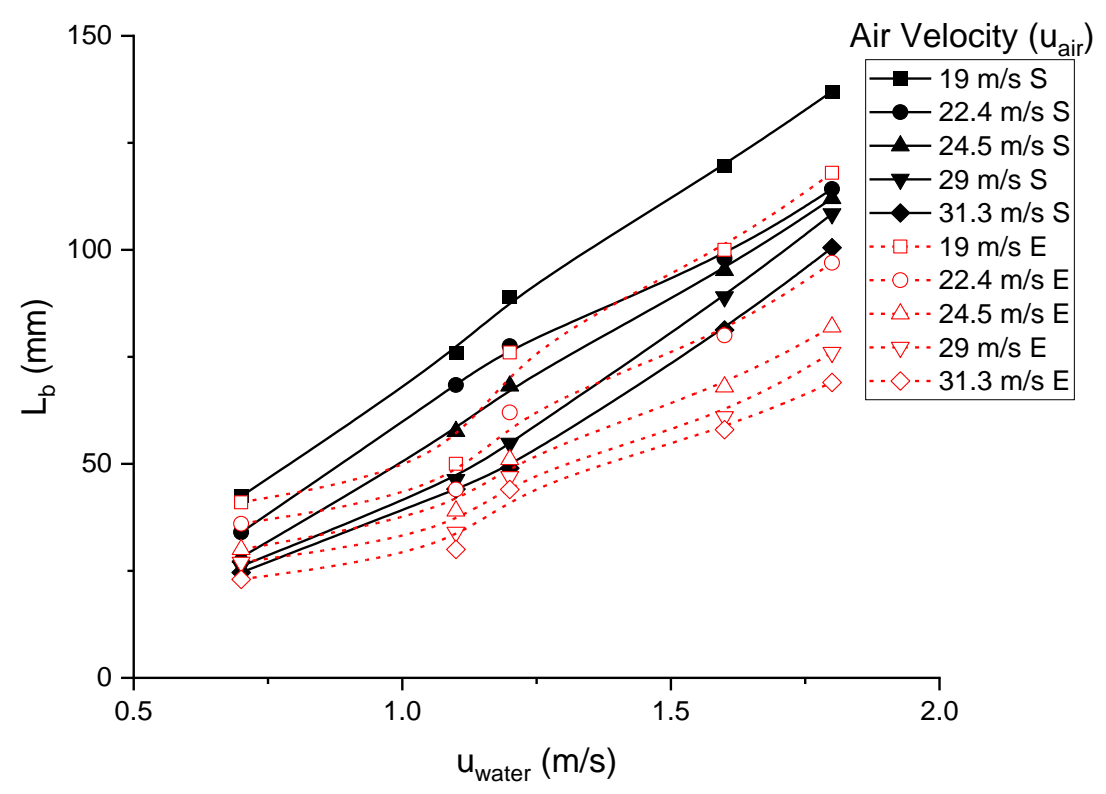

Fig. 6. Breakup length comparison with different water velocities 0.7 $\mathrm{m} / \mathrm{s}$ (Red) and $1.8 \mathrm{~m} / \mathrm{s}$ (Black)

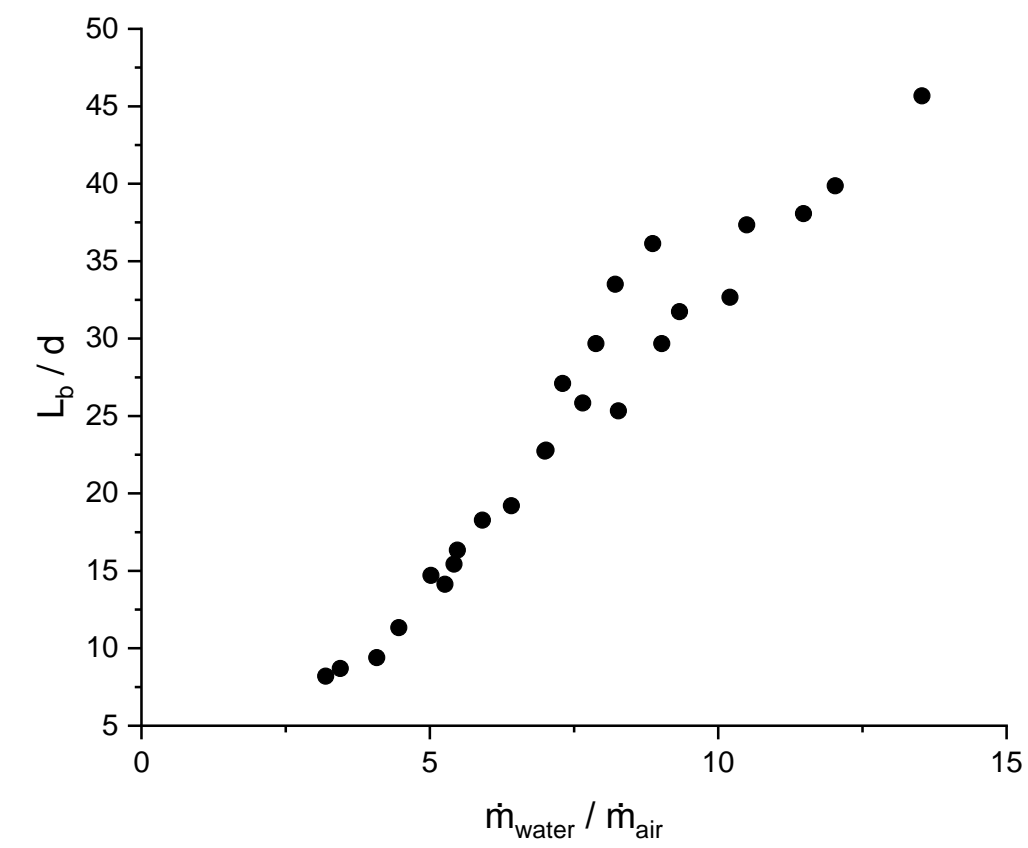

Fig. 7. Breakup length distribution at different relative mass flow rate

$$
\begin{aligned}
& \dot{m}_{\text {water }}=0.25 \times \pi \times d^{2} \times \rho_{\text {water }} \times u_{\text {water }} \\
& \dot{m}_{\text {air }}=0.25 \times \pi \times\left(d_{1}{ }^{2}-d_{0}{ }^{2}\right) \times \rho_{\text {air }} \times u_{\text {air }}
\end{aligned}
$$

\section{Conclusions}

The breakup length is observed in the primary breakup region. The breakup that occurs here comes under the fluid thread breakup process. Here, the liquid jet first thins out before breaking up. The general trend of the increase in breakup length for an increase in water velocity or a decrease in 
air velocity was observed in both the simulation and the experimental data. This was observed in Figure 5(a) to Figure 5(e). The relative mass flow rate in Figure 7 indicates which of the two fluids have a higher influence. A lower value indicates that the air stream has a higher influence on the spray and a higher value indicates that the liquid water jet has a higher influence. When the air stream has a higher influence, an aerodynamic shear breakup occurs. The pressure differences between the faster-flowing air and the slower moving water creates an aerodynamic shearing effect on the liquid jet which causes it to break up. When the water has a higher mass flow rate influence, the aerodynamic shear effect alone is not enough to cause liquid breakup, since the aerodynamics forces are negligible for the high mass flow rate of water. Hence, the surface tension over the interface between the water jet and the airflow causes the jet to elongate slowly and break up. However, since the force breaking up the liquid jet is lower than the aerodynamic shear effect, the breakup length observed in this type of breakup is higher. At lower water and air velocities, the computational data closely follows the experimental data, whereas for higher water velocities, the simulation data differs from the experimental data. The experimental data differs from the simulation data at an average of $+19 \%$. This difference is within the acceptable range. With this validated model, the spray characteristics for various working fluids can be predicted. Further, this model can be used to predict the spray characteristics of a swirl atomizer.

\section{Acknowledgement}

This research was not funded by any grant.

\section{References}

[1] Sivadas, V., K. Balaji, M. Sampathkumar, M. M. Hassan, K. M. Karthik, and Koneru Saidileep. "Empirical correlation of the primary stability variable of liquid jet and liquid sheet under acoustic field." Journal of Fluids Engineering 138, no. 8 (2016). https://doi.org/10.1115/1.4033028

[2] Sivadas, V., K. Balaji, Antriksha Vishwakarma, and Sundar Ram Manikandan. "Experimental characterization of a liquid jet emanating from an effervescent atomizer." Journal of Fluids Engineering 142, no. 6 (2020). https://doi.org/10.1115/1.4046007

[3] Watanawanyoo, Pipatpong, Hirofumi Mochida, Teruyuki Furukawa, Masanori Nakamura, and Hiroyuki Hirahara. "Experimental study on the spray characteristics of an air assisted atomizer with internal mixing chamber." European Journal of Scientific Research 84, no. 4 (2012): 507-521.

[4] Lefebvre, Arthur H., and Vincent G. McDonell. Atomization and sprays. CRC Press, 2017.

[5] Chigier, Norman. "Spray science and technology." In PICAST'1 1993- Pacific International Conference on Aerospace Science and Technology, National Cheng Kung University, Tainan, Taiwan, pp. 35-52. 1993.

[6] Liu, Alex B., Daniel Mather, and Rolf D. Reitz. "Modeling the effects of drop drag and breakup on fuel sprays." SAE Transactions (1993): 83-95. https://doi.org/10.4271/930072

[7] Fraser, R. P., N. Dombrowski, and J. H. Routley. "The atomization of a liquid sheet by an impinging air stream." Chemical Engineering Science 18, no. 6 (1963): 339-353. https://doi.org/10.1016/0009-2509(63)80027-5

[8] Bayvel, L., and Zdzislaw Orzechowski. Liquid atomization. Routledge, 2019. https://doi.org/10.1201/9780203748787

[9] Soni, Surendra Kumar, and Pankaj S. Kolhe. "Liquid jet breakup and spray formation with annular swirl air." $\begin{array}{llllll}\text { International Journal of } & \text { Multiphase } & \text { Flow } & 134 & \text { (2021): } & 103474 .\end{array}$ https://doi.org/10.1016/j.ijmultiphaseflow.2020.103474

[10] Wang, Fujun, and Tiegang Fang. "Liquid jet breakup for non-circular orifices under low pressures." International Journal of Multiphase Flow 72 (2015): 248-262. https://doi.org/10.1016/j.ijmultiphaseflow.2015.02.015

[11] Agrawal, Meenu, A. R. Premlata, Manoj Kumar Tripathi, Badarinath Karri, and Kirti Chandra Sahu. "Nonspherical liquid droplet falling in air." Physical Review $E$ 95, no. 3 (2017): 033111. https://doi.org/10.1103/PhysRevE.95.033111

[12] Balla, Mounika, Manoj Kumar Tripathi, and Kirti Chandra Sahu. "Shape oscillations of a nonspherical water droplet." Physical Review E 99, no. 2 (2019): 023107. https://doi.org/10.1103/PhysRevE.99.023107 
[13] Murugan, Raju, Pankaj S. Kolhe, and Kirti Chandra Sahu. "A combined experimental and computational study of flow-blurring atomization in a twin-fluid atomizer." European Journal of Mechanics-B/Fluids 84 (2020): 528-541. https://doi.org/10.1016/j.euromechflu.2020.07.008

[14] Soni, Surendra Kumar, Pavan Kumar Kirar, Pankaj Kolhe, and Kirti Chandra Sahu. "Deformation and breakup of droplets in an oblique continuous air stream." International Journal of Multiphase Flow 122 (2020): 103141. https://doi.org/10.1016/i.ijmultiphaseflow.2019.103141

[15] Lefebvre, Arthur H., and Dilip R. Ballal. Gas turbine combustion: alternative fuels and emissions. CRC Press, 2010. https://doi.org/10.1201/9781420086058

[16] Andsaler, Adiba Rhaodah, Amir Khalid, Nor Sharifhatul Adila Abdullah, Azwan Sapit, and Norrizam Jaat. "The effect of nozzle diameter, injection pressure and ambient temperature on spray characteristics in diesel engine." In Journal of Physics: Conference Series, vol. 822, no. 1, p. 012039. IOP Publishing, 2017. https://doi.org/10.1088/1742-6596/822/1/012039

[17] Broumand, Mohsen, Mahmoud MA Ahmed, and Madjid Birouk. "Experimental investigation of spray characteristics of a liquid jet in a turbulent subsonic gaseous crossflow." Proceedings of the Combustion Institute 37, no. 3 (2019): 3237-3244. https://doi.org/10.1016/i.proci.2018.08.004

[18] Aly, Hossam S., Yehia A. Eldrainy, Tholudin M. Lazim, and Mohammad Nazri Mohd Jaafar. "On the contribution of drag and turbulent stresses in the fragmentation of liquid droplets: a computational study." CFD Letters 2, no. 2 (2010): 97-105.

[19] Jaat, Norrizam, Amir Khalid, Norrizal Mustaffa, Fathul Hakim Zulkifli, Norshuhaila Mohamed Sunar, Ridwan Saputra Nursal, Mahmod Abd Hakim Mohamad, and Djamal Didane. "Analysis of injection pressure and high ambient density of biodiesel spray using computational fluid dynamics." CFD Letters 11, no. 1 (2019): 28-39.

[20] Seraj, Mohd, and Syed Mohd Yahya. "Numerical Study of Droplet Motion inside Non-woven Fibrous Media." CFD Letters 11, no. 5 (2019): 72-79.

[21] Jumadi, Rozita, Amir Khalid, Norrizam Jaat, Iqbal Shahridzuan Abdullah, Nofrizalidris Darlis, Bukhari Manshoor, Azahari Razali, Azwan Sapit, and Ridwan Saputra Nursal. "Analysis of Spray Characteristics and High Ambient Pressure in Gasoline Direct Injection using Computational Fluid Dynamics." CFD Letters 12, no. 5 (2020): 36-51. https://doi.org/10.37934/cfdl.12.5.3651

[22] Shafaee, Maziar, and Sajad Mahmoudzadeh. "Numerical investigation of spray characteristics of an air-blast atomizer with dynamic mesh." Aerospace Science and Technology 70 (2017): $351-358$. https://doi.org/10.1016/i.ast.2017.08.024

[23] Behr, M., D. Hastreiter, S. Mittal, and T. E. Tezduyar. "Incompressible flow past a circular cylinder: dependence of the computed flow field on the location of the lateral boundaries." Computer Methods in Applied Mechanics and Engineering 123, no. 1-4 (1995): 309-316. https://doi.org/10.1016/0045-7825(94)00736-7

[24] Prakash, R. Surya, Anubhav Sinha, Gaurav Tomar, and R. V. Ravikrishna. "Liquid jet in crossflow-effect of liquid entry conditions." Experimental Thermal and Fluid Science $93 \quad$ (2018): 45-56. https://doi.org/10.1016/j.expthermflusci.2017.12.012

[25] Sivadas, V., S. Karthick, and K. Balaji. "Symmetric and asymmetric disturbances in the Rayleigh zone of an airassisted liquid sheet: theoretical and experimental analysis." Journal of Fluids Engineering 142, no. 7 (2020). https://doi.org/10.1115/1.4045998

[26] Sivadas, Vayalakkara, K. Balaji, I. Krishna Raj, E. Vignesh, and R. Aravind. "Area Void Fraction Associated With TwinFluid Atomizer." Atomization and Sprays 23, no. 8 (2013). https://doi.org/10.1615/AtomizSpr.2013007456 